\title{
LC/MS for the degradation profiling of cough-cold products under forced conditions
}

\author{
A. Marín ${ }^{\text {a,b }}$, C. Barbas ${ }^{\text {a,* }}$

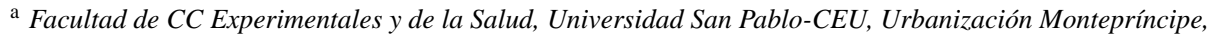 \\ Boadilla del Monte, 28668 Madrid, Spain \\ ${ }^{\mathrm{b}}$ European Analytical Technologies, DCRT Alcobendas, Lilly SA, Avda. de la Industria 30, Alcobendas, 28108 Madrid, Spain
}

Received 13 January 2004; received in revised form 22 March 2004; accepted 22 March 2004

Available online14 May 2004

\begin{abstract}
Heat, acid, base, UV radiation and oxidation stress methods were applied to study the stability of cough-cold products containing acetaminophen, phenylephrine or phenylpropanolamine hydrochloride and chlorpheniramine maleate. Liquid chromatography coupled with mass spectrometry was used to analyze the degraded samples and obtain molecular weights information. Different volatile buffers (ammonium bicarbonate and ammonium acetate) were assayed in LC/MS methods and retention times of the analytes were compared with those obtained in HPLC with UV detection employing a conventional sodium phosphate buffer to establish the possibility of results transference between the two systems.
\end{abstract}

(c) 2004 Elsevier B.V. All rights reserved.

Keywords: Acetaminophen; Phenylephrine; Phenylpropanolamine; Chlorpheniramine; Stability

\section{Introduction}

Pharmaceutical formulations against the common cold use to contain acetaminophen, phenylephrine or phenylpropanolamine hydrochloride and chlorpheniramine maleate. Acetaminophen presents known impurities commercially available such as 4-aminophenol, 4-chloracetanilide and 4-nitrophenol, but this is not the case with the other compounds. To establish the stability characteristics and degradation pathways of these compounds, forced degradation studies (stress

\footnotetext{
* Corresponding author. Fax: +34-91-3510475.

E-mail address: cbarbas@ceu.es (C. Barbas).
}

testing) were carried out on these drug substances under heat, acid, base, UV radiation and oxidation stress methods, as recommended the ICH guideline Q1A(R2) on stability testing of new drug substances and products [1]. Forced degradation has to demonstrate specificity when developing stability-indicating methods and for this reason it should be performed prior to implementation of stability studies to assure analytical methods are stability-indicating. With that purpose, it is necessary documented evidence that analytical procedures are validated and suitable for the detection and quantisation of degradation products, as emphasizes the $\mathrm{ICH}$ guideline $\mathrm{Q} 3 \mathrm{~B}(\mathrm{R})$ entitled "impurities in new drug products" [2]. It is also required that analytical methods should be validated to 
demonstrate that impurities unique to the new drug substance do not interfere with, or are separated from, specified and unspecified degradation products in the drug products.

The techniques employed for the analysis of stability samples can be titrimetric, spectophotometric and chromatographic methods. A critical review of these methods is shown in the work of Bakshi and Singh [3]. Within the chromatographic methods, HPLC is the most employed due to its high-resolution capacity, sensitivity and specificity, and because a lot of compounds can be analysed using this technique. Nevertheless, some times the information that supplies the HPLC is not enough for identity confirmation of known and unknown degradation products and their selective determination. For this purpose, hyphenated LC/MS technique that supplies molecular weight and fragmentation information is an indispensable tool of analysis. But in many cases, method development is required because HPLC/UV methods are not easily transferred to LC/MS due to many of the HPLC applications require non-volatile buffer solutions for optimal separation that the LC and MS interface does not tolerate.

The objective of this study was the transference of a HPLC method with a phosphate buffer to the LC/MS system for the determination of the impurity profiling of the components of a cough-cold formulation, employing volatile buffers like ammonium bicarbonate and ammonium acetate.

\section{Experimental}

\subsection{Chemicals}

Standards of actives (acetaminophen, phenylephrine, phenylpropanolamine and chlorpheniramine maleate) and impurities (4-aminophenol, 4-chloracetanilide and 4-nitrophenol) as well as capsules, and excipients of the specialities were kindly provided by CINFA, S.A. (Pamplona, Spain). $\mathrm{NaOH}$ and $\mathrm{H}_{2} \mathrm{O}_{2}$ were from Panreac (Barcelona, Spain), $\mathrm{H}_{3} \mathrm{PO}_{4}$, $\mathrm{NH}_{4} \mathrm{COOCH}_{3}$ and $\mathrm{CH}_{3} \mathrm{CN}$ (HPLC) from Merck (Darmstadt, Germany), $\mathrm{NH}_{4} \mathrm{HCO}_{3}$ was from SigmaAldrich (Steinheim, Germany), $\mathrm{HCl}$ was from Carlo Erba and water was purified with a Milli-Q plus system from Millipore (Bedford, MA, USA).

\subsection{HPLC analysis}

The system consisted of an Agilent Technologies 1100 liquid chromatograph (Las Rozas, Madrid, España) with a quaternary pump, an automatic injector, a diode-array detector and a column oven. The chromatographic analysis were performed on a $5 \mu \mathrm{m}$ particle, Discovery HS PEG (polyethylene glycol) column (Supelco, Alcobendas, Madrid, Spain), $15 \mathrm{~cm} \times 0.46 \mathrm{~cm}$, kept at $35^{\circ} \mathrm{C}$.

The mobile phase was phosphate buffer $20 \mathrm{mM}$ at $\mathrm{pH} 7.0 /$ acetonitrile, 90/10 (v/v). The phosphate buffer was prepared from $\mathrm{H}_{3} \mathrm{PO}_{4}$ by adding $\mathrm{NaOH}$ to reach the $\mathrm{pH}$ 7.0. The flow rate was $1 \mathrm{ml} / \mathrm{min}$ and the injection volume was $5 \mu$ l. UV detection was performed at 215 and $254 \mathrm{~nm}$.

\subsection{LC/MS analysis}

HPLC experiments were carried out on an Agilent Technologies 1100 LC. Electrospray mass spectrometry measurements were performed on a MSD quadrupole mass spectrometer (Agilent Technologies, Palo Alto, CA, USA) interface to the 1100 HPLC system. MS measurements were acquired simultaneously in both positive and negative ion full scan modes from 50 to 600 , using $80 \mathrm{~V}$ of fragmentator voltage to determine the molecular weights of the degradants. Drying gas flow and temperature were $13 \mathrm{l} / \mathrm{min}$ and $350^{\circ} \mathrm{C}$, respectively. The nebulizador pressure was $60 \mathrm{psi}$ and the capillary voltage $2500 \mathrm{~V}$. Data acquisition and integration for LC-UV and MS detection were collected using HP Chemstation software (Agilent Technologies).

The chromatographic conditions employed were:

\subsubsection{Method 1}

The chromatographic separation was performed on a XTerra RP C18 column $250 \mathrm{~mm} \times 4.6 \mathrm{~mm}, 5 \mu \mathrm{m}$ (Waters, Milford, MA, USA) kept at $35^{\circ} \mathrm{C}$. Chromatographic conditions were a gradient elution, being solvent $\mathrm{A}: 10 \mathrm{mM}$ ammonium bicarbonate $\left(\mathrm{NH}_{4} \mathrm{HCO}_{3}\right)$ at $\mathrm{pH} 8$ and solvent $\mathrm{B}$ : acetonitrile $\left(\mathrm{CH}_{3} \mathrm{CN}\right)$. At $t=0$ the mobile phase consisted of $95 \% \mathrm{~A}$ and $5 \% \mathrm{~B}$ and it changed with a linear gradient during $15 \mathrm{~min}$ to $25 \% \mathrm{~A}$ and $75 \% \mathrm{~B}$. At $15 \mathrm{~min}$ it changed to $95 \% \mathrm{~B}$ for $2 \mathrm{~min}$ and at $t=17 \mathrm{~min}$ it returned to the initial conditions (5\% B) during 1 min remaining at this composition until $t=20 \mathrm{~min}$. 


\subsubsection{Method 2}

The chromatographic analysis was performed on a Discovery HS polyethyleneglycol (PEG) column $150 \mathrm{~mm} \times 4.6 \mathrm{~mm}, 5 \mu \mathrm{m}$ (Supelco, Alcobendas, Madrid, Spain), kept at $35^{\circ} \mathrm{C}$. The mobile phase was $10 \mathrm{mM}$ ammonium acetate at $\mathrm{pH} 7 /$ acetonitrile, 90/10 $(\mathrm{v} / \mathrm{v})$.

In both methods, UV detection was performed at 215 and $254 \mathrm{~nm}$, the injection volume was $5 \mu \mathrm{l}$ and the flow rate prior to the mass spectrometer was $1 \mathrm{ml} / \mathrm{min}$, which was split at a ratio of 3:1 in order to deliver $250 \mu \mathrm{l} / \mathrm{min}$ into the electrospray interface and $750 \mu \mathrm{l} / \mathrm{min}$ to the waste reservoir.

\subsection{Standards and sample preparation}

Solutions of standards and impurities were prepared by dissolving $100 \mathrm{mg}$ of each compound in a mixture of water/acetonitrile, 75:25 (v/v), and making-up the solution to $100 \mathrm{ml}$.

Solution of sample was prepared by dissolving $610 \mathrm{mg}$ of sample (the approximate weight of one capsule, containing $500 \mathrm{mg}$ of acetaminophen, $10 \mathrm{mg}$ of phenylephrine hydroclorure, $4 \mathrm{mg}$ of chlorpheniramine maleate and $96 \mathrm{mg}$ of excipients), coming from 20 capsules homogenate, in a mixture of water/acetonitrile, 75:25 (v/v), and making-up the solution to $50 \mathrm{ml}$.

Excipients were prepared by dissolving $96 \mathrm{mg}$ of a homogeneous mixture of the excipients components (starch, aerosil, talc and magnesium stearate) with the same qualitative composition that the pharmaceutical formulation, in a mixture of water/acetonitrile, 75:25 $(\mathrm{v} / \mathrm{v})$, and making-up the solution to $50 \mathrm{ml}$.

\subsection{Forced degradation conditions}

To carry out the forced degradation assay, standards, impurities, sample and excipients solutions were treated with the following conditions:

(a) Acid conditions: Solutions were acidulated with $37 \% \mathrm{HCl}$ to reach the $\mathrm{pH} 2.0$, for $24 \mathrm{~h}$. After the degradation treatment was complete, all the solutions were neutralized with $1 \mathrm{~N} \mathrm{NaOH}$ until initial $\mathrm{pH}$.

(b) Basic conditions: Solutions were treated with $1 \mathrm{~N}$ $\mathrm{NaOH}$ to reach the $\mathrm{pH} 10.0$, for $24 \mathrm{~h}$. After the degradation treatment was complete, all the solutions were neutralized with $37 \% \mathrm{HCl}$ until initial $\mathrm{pH}$.

(c) Oxidation with $\mathrm{H}_{2} \mathrm{O}_{2}$ : Solutions were treated with $\mathrm{H}_{2} \mathrm{O}_{2}$ for $24 \mathrm{~h}$.

(d) Heat: Solutions were heated to $80^{\circ} \mathrm{C}$ for $1 \mathrm{~h}$.

(e) UV radiation: Solutions were exposed under a $254 \mathrm{~nm}$ light during $48 \mathrm{~h}$.

Once the different treatments were complete, all the solutions and blanks (solutions without any treatment) were filtered with a $0.45 \mu \mathrm{m}$ syringe filtration disk to the vials for injection in the HPLC and LC/MS system.

\section{Results and discussion}

\subsection{LC/MS method optimization}

In the previous work, we developed and validated a HPLC method for the simultaneous determination of acetaminophen, phenylephrine and chlorpheniramine in pharmaceutical formulations such as capsules and sachets. It included the separation of impurities, excipients and phenylpropanolamine, which can be contained in some formulations instead of phenylephrine. The method was a gradient elution in a Symmetry Shield RP8 [4]. The run lasted for $20 \mathrm{~min}$. The method was employed for stability assays, but it presented the problems related to gradient elution like baseline shifts and irregular elution of unknown retained compounds. These usually came from water, when the organic solvent proportion increased, which complicated the analysis of related compounds.

In order to solve the problems of the gradient elution, we developed and validated an isocratic HPLC method for the simultaneous determination of the three actives, acetaminophen, phenyleprine and chlorpheniramine in capsules as pharmaceutical formulations, including the separation of impurities and excipients. The chromatographic method was an interesting advance because it was isocratic and its run time was less than $12 \mathrm{~min}$. It was developed by using new polar reverse phase stationary phases in HPLC, such as polyethyleneglycol, which provided with specific selectivity [5]. However, in both cases, gradient and isocratic elution, $40 \mathrm{mM}$ potassium and $20 \mathrm{mM}$ 
sodium phosphate buffers were used as aqueous phase at $\mathrm{pH} 6$ and 7, respectively.

These types of buffers at high concentrations are incompatible when we use MS detector because deposition of the buffer occurs at the ionization source leading to loss of sensitivity and down time when the ion source has to be cleaned [6,7].

For this reason, in order to analyse the degraded samples and to do a tentative structural identifications based on their molecular weight measurements of the degradation products, it was necessary to develop a LC/MS method. Atmospheric pressure ionization (API), was used as interface. ESI was chosen as the ionization mode, because the cough-cold compounds of this study are ions in solution and some of the interest compounds like phenylephrine and phenylpropanolamine are very polar. The chemical structures of the assayed compounds and most of their values for the acid-base constants are shown in Table 1. The selection of a correct detection polarity (positive and negative mode) is based mostly on the characteristics of the solutes. For this work, both positive and negative ions were recorded in the same chromatographic run, by continuously alternating the voltage on the capillary of the MS inlet, because acidic and basic degraded compounds can be presented in the same samples [8].

Other important considerations when using MS as the detection system, like buffer type and concentration, type of organic modifier and HPLC column, were taken [7]. As previously mentioned, volatile constituents (solvents, buffers, additives) in the mobile phase should be selected whenever possible [9]. For the selection of the aqueous mobile phase in addition to volatility, the $\mathrm{pH}$ was a critical point because as it is well known, the selectivity and retention of basic compounds is highly dependent of the mobile phase and proper buffer $\mathrm{pH}[10,11]$. In our previous works we observed that the best results were obtained working around $\mathrm{pH} 7$ [5,12]. Two different volatile buffers were tested in the development of the LC/MS method. One of them was the ammonium bicarbonate at $\mathrm{pH}$ 8. The good properties of this buffer for its use in HPLC/UV/MS, such as the excellent MS ionization, peak shape, its buffer capacity, reproducible results, and its stability at room temperature, decomposing at temperatures above $60^{\circ} \mathrm{C}$ to form ammonia, carbon dioxide and water, have been described in the works of Espada and co-workers [13,14].
The other buffer considered in this study was the ammonium acetate at $\mathrm{pH} 7$. Although it is not a buffer at $\mathrm{pH} 7$, it is often used at this $\mathrm{pH}$ in LC/MS. It gives the same efficiency as ammonium phosphate, and does not present problems of reduced precision of retention times [6].

The concentration of both buffers was $10 \mathrm{mM}$, which is the most common value in LC/MS. As organic modifier we chose acetonitrile instead of methanol, in order to obtain the maximum UV sensitivity at low wavelengths.

For the column selection, the $\mathrm{pH} 8$ of the ammonium bicarbonate was the determinant factor because the traditional silica-based C18 columns are unable to operate for any useful period of time above $\mathrm{pH}$ 7.5. Nowadays, there are new packing materials that are designed to cover a wide range of $\mathrm{pH}(1-12)$ such as XTerra or Zirconia-based columns, without suffering hydrolysis below pH 2 [15], and with no dissolution of the silica with the attack of the ions $\left(\mathrm{OH}^{-}\right)$ above $\mathrm{pH} 8$ [16]. For this study we chose XTerra column which is a reversed-phase HPLC packing based on hybrid particles, that combines the high efficiency and excellent mechanical strength of bonded silica phases with the best properties of organic polymers, such as wide $\mathrm{pH}$ stability range and absence of silanol effects [17]. Due to the different polarity and, therefore, chromatographic behaviour of the active compounds and impurities of this study, it was necessary to develop a gradient method. A linear gradient from 5 to $75 \%$ of acetonitrile in $15 \mathrm{~min}$ on a XTerra RP $\mathrm{C} 18,5 \mu \mathrm{m}, 4.6 \mathrm{~mm} \times 250 \mathrm{~mm}$ allowed us to separate all the actives and the impurities in $20 \mathrm{~min}$ of run. The chromatogram is shown in Fig. 1. Nevertheless, this method showed a problem due to its different selectivity in comparison with the HPLC/UV method on the polyethyleneglycol column. For this reason we decided to test the polyethyleneglycol column under the same isocratic conditions that the validated method used for the measurement of the samples. However, we replaced the phosphate buffer at pH 7 with a volatile buffer compatible with MS like the $10 \mathrm{mM}$ ammonium acetate at $\mathrm{pH}$ 7. In Fig. 2, a comparison of the retention times of the actives and impurities with the two different methods developed for the measurements of the degraded products by LC/MS, with the HPLC/UV method is presented. Significant differences were found when comparing the 
Table 1

Chemical structures of the assayed compounds and their values for the acid-base constants

\begin{tabular}{|c|c|c|c|c|c|c|c|c|}
\hline Name & $\begin{array}{l}\text { Molecular } \\
\text { form }\end{array}$ & Estructural form & $\begin{array}{l}\text { Molecular } \\
\text { weight }\end{array}$ & $\begin{array}{l}\text { Exact } \\
\text { mass }\end{array}$ & $m / z(\mathrm{ESI}+)$ & $\mathrm{p} K_{\mathrm{a}}$ & Reference & $\mathrm{p} K_{\mathrm{a}}(\mathrm{ACD} \mathrm{Lab})$ \\
\hline Acetaminophen & $\mathrm{C}_{8} \mathrm{H}_{9} \mathrm{NO}_{2}$ & & 151.17 & 151 & $\begin{array}{ll}m / z & 152[\mathrm{M}+\mathrm{H}] \\
m / z & 174[\mathrm{M}+\mathrm{Na}] \\
m / z & 325[2 \mathrm{M}+\mathrm{Na}]\end{array}$ & 9.5 & & $\begin{aligned} 15.32 & \pm 0.70(\mathrm{NH}) \\
9.86 & \pm 0.13(\mathrm{OH}) \\
-0.14 & \pm 0.50\left(\mathrm{NH}_{2}^{+}\right)\end{aligned}$ \\
\hline Phenylephrine & $\mathrm{C}_{9} \mathrm{H}_{13} \mathrm{NO}_{2}$ & & 167.21 & 167 & $m / z 168[\mathrm{M}+\mathrm{H}]$ & 8.9 and 10.1 & [18] & $\begin{aligned} 14.32 & \pm 0.20(\mathrm{OH}) \\
9.76 & \pm 0.10(\mathrm{OH} \text { phenol }) \\
9.22 & \pm 0.20\left(\mathrm{NH}_{2}^{+}\right)\end{aligned}$ \\
\hline Phenylpropanolamine & $\mathrm{C}_{9} \mathrm{H}_{13} \mathrm{NO}$ & & 151.21 & 151 & $m / z 152[\mathrm{M}+\mathrm{H}]$ & $9.44 \pm 0.04$ & {$[19,20]$} & $\begin{aligned} 12.07 & \pm 0.45(\mathrm{OH}) \\
8.47 & \pm 0.10\left(\mathrm{NH}_{3}{ }^{+}\right)\end{aligned}$ \\
\hline Chlorpheniramine & $\mathrm{C}_{16} \mathrm{H}_{19} \mathrm{ClN}_{2}$ & & 274.80 & 274 & $\begin{array}{l}m / z 275[\mathrm{M}+\mathrm{H}] \\
m / z 277\left({ }^{37} \mathrm{Cl}\right)\end{array}$ & 9.1 & {$[19,20]$} & $\begin{array}{l}9.33 \pm 0.28\left(\mathrm{NH}^{+}\right) \\
3.77 \pm 0.19\left(\mathrm{NH}^{+} \text {pyridine }\right)\end{array}$ \\
\hline 4-Aminophenol & $\mathrm{C}_{6} \mathrm{H}_{7} \mathrm{NO}$ & & 109.13 & 109 & $m / z 110[\mathrm{M}+\mathrm{H}]$ & 10.46 & & $\begin{aligned} 10.17 & \pm 0.13(\mathrm{OH}) \\
5.28 & \pm 0.10\left(\mathrm{NH}_{3}{ }^{+}\right)\end{aligned}$ \\
\hline 4-Chloracetanilide & $\mathrm{C}_{8} \mathrm{H}_{8} \mathrm{ClNO}$ & & 169.61 & 169 & $\begin{array}{ll}m / z & 170[\mathrm{M}+\mathrm{H}] \\
m / z & 172\left({ }^{37} \mathrm{Cl}\right)\end{array}$ & & & $\begin{aligned} 14.25 & \pm 0.70(\mathrm{NH}) \\
-1.97 & \pm 0.50\left(\mathrm{NH}_{2}^{+}\right)\end{aligned}$ \\
\hline 4-Nitrophenol & $\mathrm{C}_{6} \mathrm{H}_{5} \mathrm{NO}_{3}$ & $\mathrm{NO}_{2}$ & 139.11 & 139 & $m / z 140[\mathrm{M}+\mathrm{H}]$ & & & $7.23 \pm 0.13(\mathrm{OH})$ \\
\hline
\end{tabular}




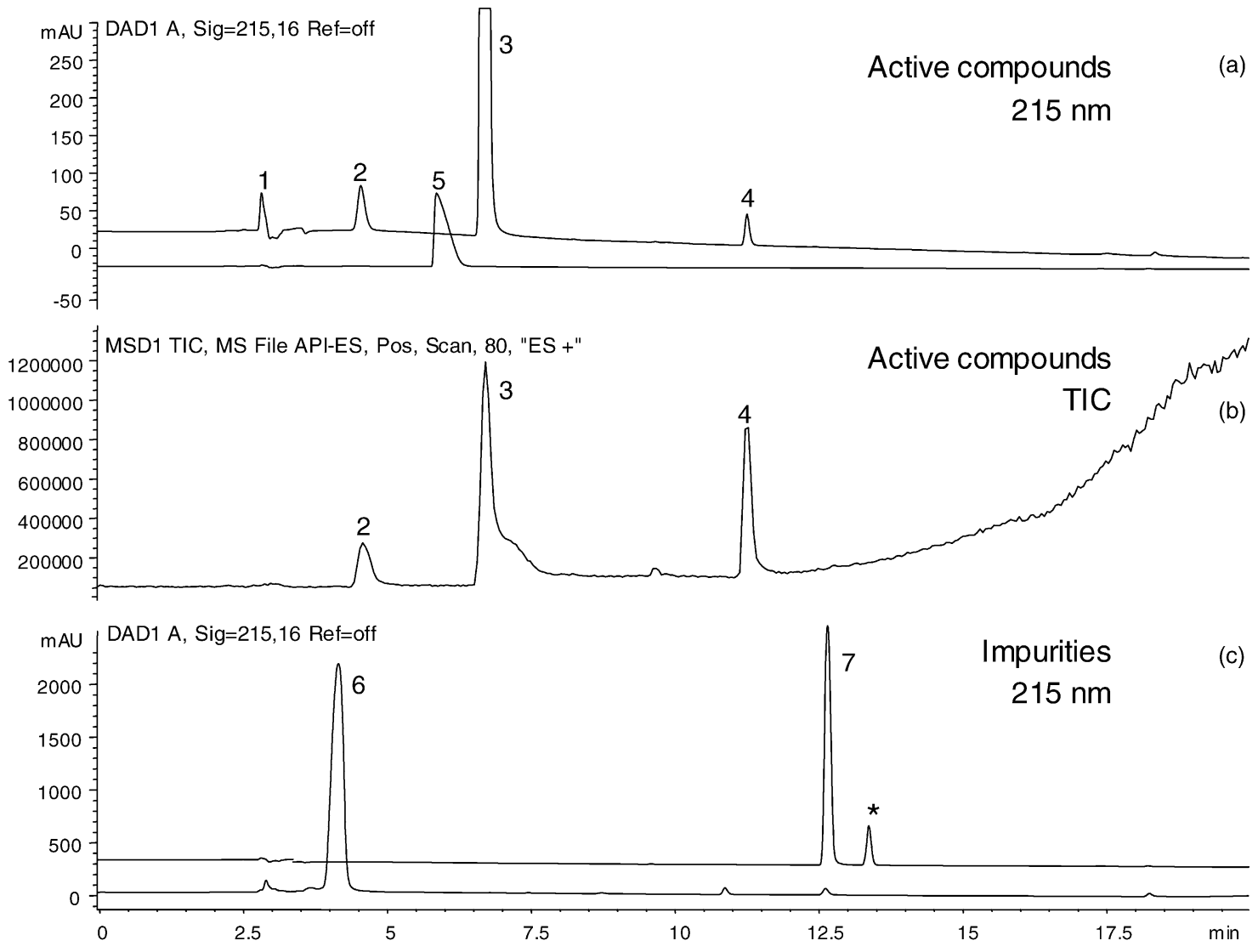

Fig. 1. Chromatograms of the active compounds and the impurities obtained with the LC/MS method on the XTerra MS C18 $(5 \mu \mathrm{m}$, $4.6 \mathrm{~mm} \times 250 \mathrm{~mm}$ ) (waters). Mobile phases: A: ammonium bicarbonate B: acetonitrile. Gradient modes: from 5 to $75 \%$ B in $15 \mathrm{~min}$ and $95 \% \mathrm{~B}$ in $2 \mathrm{~min}$. Flow: $1 \mathrm{ml} / \mathrm{min}, \lambda: 215 \mathrm{~nm}$. Temperature: $35^{\circ} \mathrm{C}$ (a) and (b) active compounds: 1: maleate, 2: phenylephrine, 3 : acetaminophen and 4: chlorpheniramine, 5: phenylpropanolamine. (c) Impurities: 6: 4-aminophenol, 7: 4-chloracetanilide and *: Impurity of 4-chloracetanilide.

polyethyleneglycol (PEG) phase with the XTerra RP C18 using ammonium bicarbonate at $\mathrm{pH} 8$, because PEG phase has ether groups that can attract other polar analytes. It also provides a very different separation of phenols (phenylephrine, acetaminophen, 4-aminophenol) compared to $\mathrm{C} 18$, and faster analysis, because it presents lower retention for non polar compounds like chlorpheniramine that eluted late on C18. This permitted us to work with isocratic conditions, shorter run time and higher reproducibility. On the other hand, very similar results were obtained in the polyethyleneglycol column using phosphate buffer and ammonium acetate at $\mathrm{pH}$ 7. A comparison of the chromatograms of the actives compounds (acetaminophen, phenylephrine and chlorpheniramine) and the impurities (4-aminophenol, 4-chloracetanilide and 4-nitrophenol) obtained with both methods is illustrated in Fig. 3.

Due to the similar selectivity of both buffers we used this last method for the determination of degraded products by LC/MS. Final chromatographic conditions consisted on a Supelco Discovery HS PEG column (polyethyleneglycol), $5 \mu \mathrm{m}$, $4.6 \mathrm{~mm} \times 150 \mathrm{~mm}$. The mobile phase was $10 \mathrm{mM}$ ammonium acetate at $\mathrm{pH}$ 7.0/acetonitrile 90:10 at a flow rate of $1 \mathrm{ml} / \mathrm{min}$. This method also permitted us to separate the maleate (co-ion of chorpheniramine) from its isomer trans, the fumarate, 


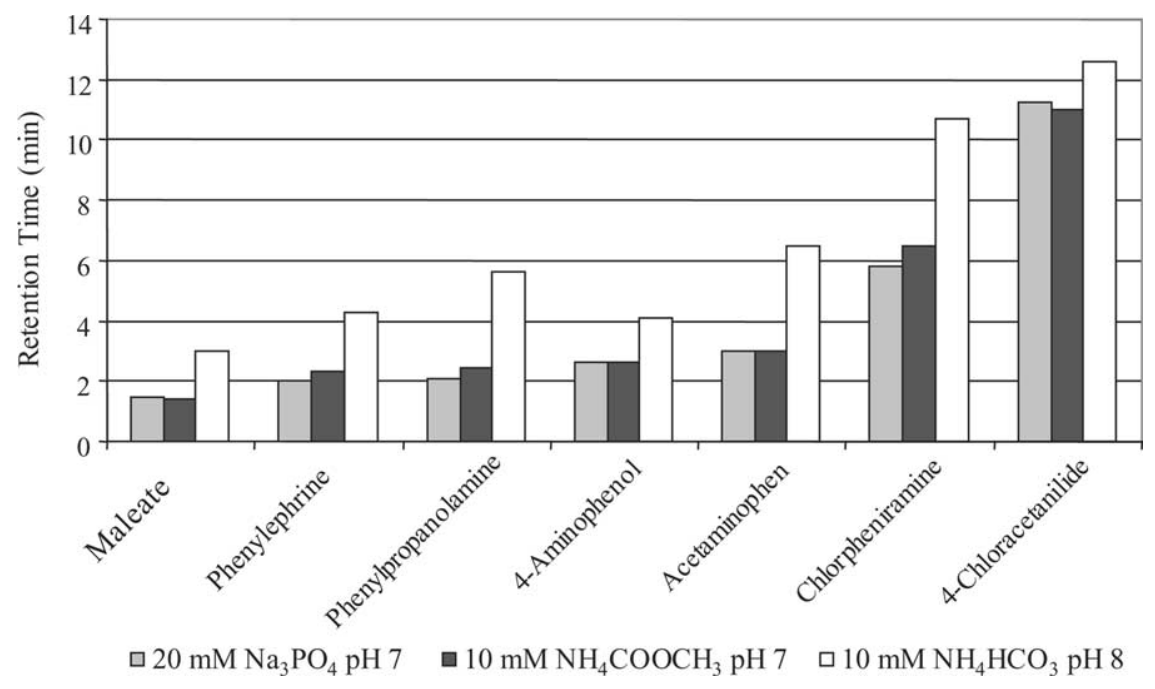

Fig. 2. Comparison of the retention times of the actives and impurities with the two LC/MS methods developed for the measurements of the degraded products using $10 \mathrm{mM}$ ammonium acetate at $\mathrm{pH} 7$ and $10 \mathrm{mM}$ ammonium bicarbonate at $\mathrm{pH} 8$ with the HPLC/UV method using $20 \mathrm{mM}$ sodium phosphate at $\mathrm{pH} 7$.

which is formed from the maleate with the effect of heat.

\subsection{Forced degradation}

Heat, acid, base, UV radiation and oxidation stress methods were applied to study the stability of cough-cold products. Once the different treatments were complete, all the solutions and blanks (solutions without any treatment) were analyzed by HPLC and LC/MS in order to ascertain the molecular weight of the degradation products.

Table 2 shows the results obtained with the standards and sample under different stress conditions. Validation of the method for quantification and the corresponding equations were previously published [5]. Results show that these cough-cold products are not affected by the heat under these forced conditions because no new peak was detected. The effect of UV radiation was insignificant, because only $0.8 \%$ of acetaminophen was degraded. Under acidic conditions, phenylephrine and phenylpropanolamine gave 1.3 and $1.2 \%$ of degradation products, respectively. Under basic conditions, phenylephrine showed $0.8 \%$ of degradation products, phenylpropanolamine $0.4 \%$ and acetaminophen $0.1 \%$. All the solutions treated with $\mathrm{H}_{2} \mathrm{O}_{2}$ during $24 \mathrm{~h}$ showed significant degradation, especially phenylephrine (5.8\%) and acetaminophen (4.7\%). Chlorpheniramine was stable under all conditions except under oxidation conditions, where $1.1 \%$ was degraded. No degradation of excipients was found under the five studied stress conditions. Samples showed different grades of degradation based on forced degradation conditions, in some cases higher than the individual components due to some degradation products are formed by combination of several of them.

Table 3 shows the retention times, mass spectra and the molecular weights of some of the degradation products detected by LC/MS.

Under acidic conditions, five additional peaks (degradation products A-E) were detected in the sample by UV (Fig. 4a) but only two of them were detected by MS as it is shown in Fig. 4b. Degradation product $\mathrm{B}$ eluted at $2.5 \mathrm{~min}$ and gave molecular ions at $m / z 210[\mathrm{M}+\mathrm{H}]^{+}, m / z 232[\mathrm{M}+\mathrm{Na}]^{+}$and $\mathrm{m} / z 441[2 \mathrm{M}+\mathrm{Na}]^{+}$, indicating it has a molecular weight of $209 \mathrm{Da}$ (Fig. 4c). Degradation product D is a compound coming from the chlorpheniramine, which eluted at $4.7 \mathrm{~min}$ and its mass spectra indicated a molecular ion at $\mathrm{m} / \mathrm{z}, 291$ and $\mathrm{m} / \mathrm{z}, 293$ from the ${ }^{37} \mathrm{Cl}$ isotope (Fig. 4d). Acidic conditions were the most harmful for the sample, showing $4.7 \%$ of degradation products. 

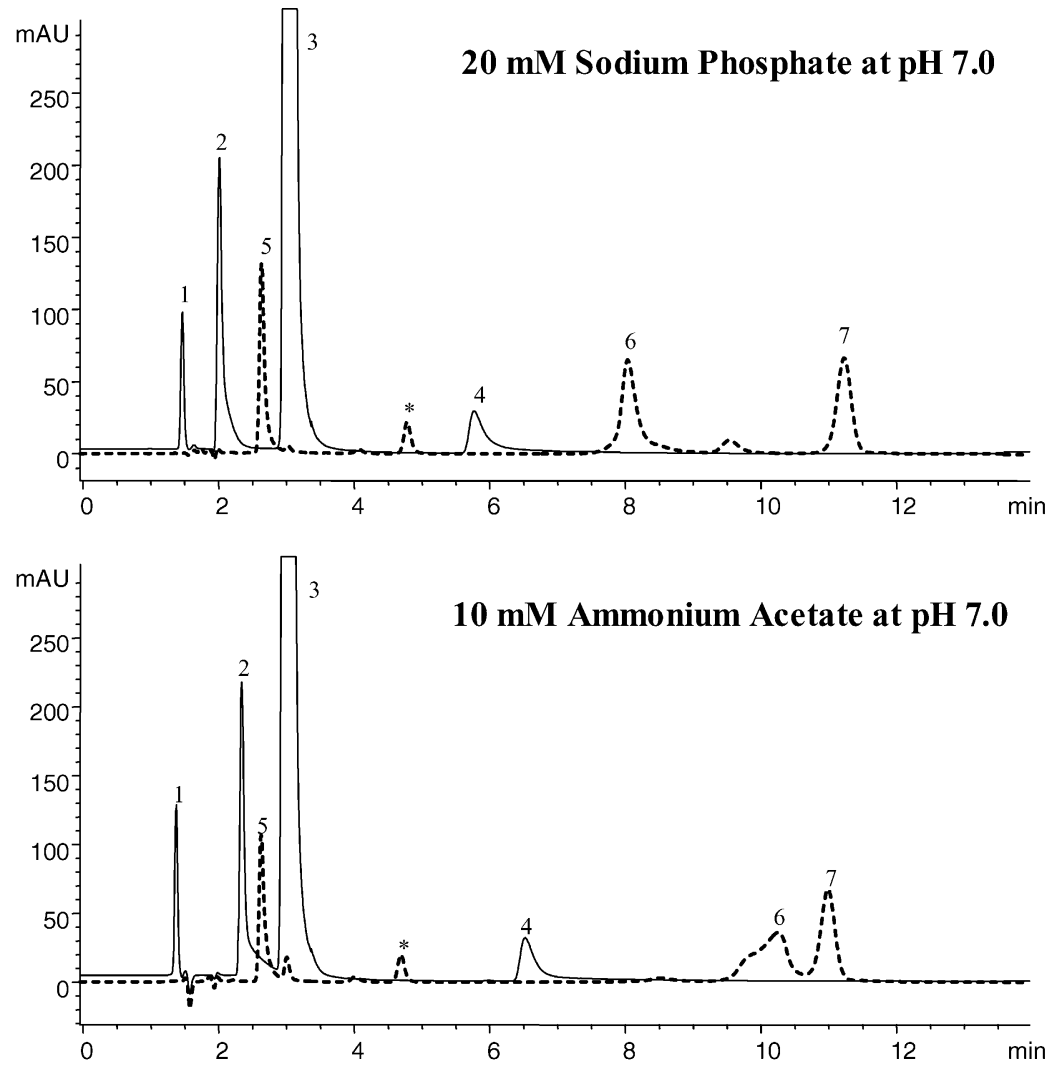

Fig. 3. Chromatograms of the actives compounds and the impurities obtained with the HPLC/UV and LC/MS methods on the discovery HS PEG (polyethyleneglycol) column $(5 \mu \mathrm{m}, 4.6 \mathrm{~mm} \times 150 \mathrm{~mm}$ ) (Supelco). Mobile phases: $90 \%$ A: $20 \mathrm{mM}$ phosphate buffer $\mathrm{pH} 7.0 \mathrm{or}$ B: $10 \mathrm{mM}$ ammonium acetate $\mathrm{pH} 7.0 / 10 \%$ acetonitrile. Flow: $1 \mathrm{ml} / \mathrm{min}$. $\lambda: 215 \mathrm{~nm}$. Temperature: $35^{\circ} \mathrm{C}$. Actives compounds: $1:$ maleate, 2 : phenylephrine $(0.2 \mathrm{mg} / \mathrm{ml}), 3$ : acetaminophen $(10 \mathrm{mg} / \mathrm{ml})$ and 4 : chlorpheniramine $(0.08 \mathrm{mg} / \mathrm{ml})$. Impurities $(0.1 \mathrm{mg} / \mathrm{ml})$ : $5:$ 4-aminophenol, 6: 4-nitrophenol and 7: 4-chloracetanilide and *: Impurity of 4-chloracetanilide.

Only one degradant generated from phenylpropanolamine was detected at 2.6 min under basic conditions (product $\mathrm{M}$ ). This compound showed molecular ions at $\mathrm{m} / z 194[\mathrm{M}+\mathrm{H}]^{+}, \mathrm{m} / z 216[\mathrm{M}+\mathrm{Na}]^{+}$and $m / z 409[2 \mathrm{M}+\mathrm{Na}]]^{+}$, which corresponds to $193 \mathrm{Da}$ of molecular weight.

The chromatogram of the sample treated with $\mathrm{H}_{2} \mathrm{O}_{2}$ showed eight different additional peaks (D,

Table 2

Stability of the standards, sample and excipients under different forced conditions ${ }^{\mathrm{a}}$

\begin{tabular}{|c|c|c|c|c|c|}
\hline Name & UV & Heat & Acid & Basic & Oxidation \\
\hline Acetaminophen $(\%)$ & 99.2 & 100 & 100 & 99.9 & 95.3 \\
\hline Phenylephrine (\%) & 100 & 100 & 98.7 & 99.2 & 94.2 \\
\hline Phenylpropanolamine (\%) & 100 & 100 & 98.8 & 99.6 & 98.1 \\
\hline Chlorpheniramine (\%) & 100 & 100 & 99.9 & 100 & 98.9 \\
\hline Sample $(\%)$ & 98.1 & 100 & 95.3 & 98.8 & 97.1 \\
\hline Excipients (\%) & 100 & 100 & 100 & 100 & 100 \\
\hline
\end{tabular}

\footnotetext{
${ }^{\text {a }}$ Expressed as unaltered compound.
} 
Table 3

Origin and mass spectra information of the degradation products detected by LC/MS

\begin{tabular}{|c|c|c|c|c|}
\hline Compound & Origin & $\mathrm{RT}(\min )$ & MW & $m / z(\mathrm{ESI}+)$ \\
\hline B & $\begin{array}{l}\text { Degradation product of the sample under acid } \\
\text { conditions }\end{array}$ & 2.5 & 209 & $\begin{array}{l}m / z 210[\mathrm{M}+\mathrm{H}]^{+}, m / z 232[\mathrm{M}+\mathrm{Na}]^{+} \\
\text {and } m / z 441[2 \mathrm{M}+\mathrm{Na}]^{+}\end{array}$ \\
\hline $\mathrm{D}$ & $\begin{array}{l}\text { Degradation product of chlorpheniramine in the } \\
\text { sample under acidic and oxidation conditions }\end{array}$ & 4.7 & 290 & $m / z 291[\mathrm{M}+\mathrm{H}]^{+}$and $m / z 293(100 / 33)$ \\
\hline M & $\begin{array}{l}\text { Degradation product of phenylpropanolamine } \\
\text { under basic conditions }\end{array}$ & 2.6 & 193 & $\begin{array}{l}m / z 194[\mathrm{M}+\mathrm{H}]^{+}, m / z 216[\mathrm{M}+\mathrm{Na}]^{+} \\
\text {and } m / z 409[2 \mathrm{M}+\mathrm{Na}]^{+}\end{array}$ \\
\hline $\mathrm{F}$ & $\begin{array}{l}\text { Degradation product of acetaminophen under } \\
\text { oxidation conditions }\end{array}$ & 1.5 & 157 & $\begin{array}{l}m / z 158[\mathrm{M}+\mathrm{H}]^{+}, m / z 180[\mathrm{M}+\mathrm{Na}]^{+} \\
\text {and } m / z 337[2 \mathrm{M}+\mathrm{Na}]^{+}\end{array}$ \\
\hline $\mathrm{H}$ & $\begin{array}{l}\text { Degradation product of phenylephrine under } \\
\text { oxidation conditions }\end{array}$ & 2.7 & 179 & $\begin{array}{l}m / z 180[\mathrm{M}+\mathrm{H}]^{+}, m / z 202[\mathrm{M}+\mathrm{Na}]^{+} \\
\text {and } m / z 381[2 \mathrm{M}+\mathrm{Na}]^{+}\end{array}$ \\
\hline G & $\begin{array}{l}\text { Degradation product of phenylephrine under } \\
\text { oxidation conditions }\end{array}$ & 1.9 & 195 & $m / z 196[\mathrm{M}+\mathrm{H}]^{+}$ \\
\hline
\end{tabular}

F-L) by UV (Fig. 5a), that constitute the $2.9 \%$ of degraded products. Four of them were detected by MS as it is shown in Fig. 5c-f. At 1.5 min a degradation product of acetaminophen (product F) was detected showing molecular ions at $\mathrm{m} / \mathrm{z} 158[\mathrm{M}+\mathrm{N}]^{+}, \mathrm{m} / \mathrm{z}$ $180\left[\mathrm{M}+\mathrm{Na}^{+}\right]$and $m / z 337[2 \mathrm{M}+\mathrm{Na}]^{+}(157 \mathrm{Da})$ (Fig. 5c). At $4.7 \mathrm{~min}$ the same degradation product of chlorpheniramine (product D) with $\mathrm{m} / \mathrm{z}, 291$ and
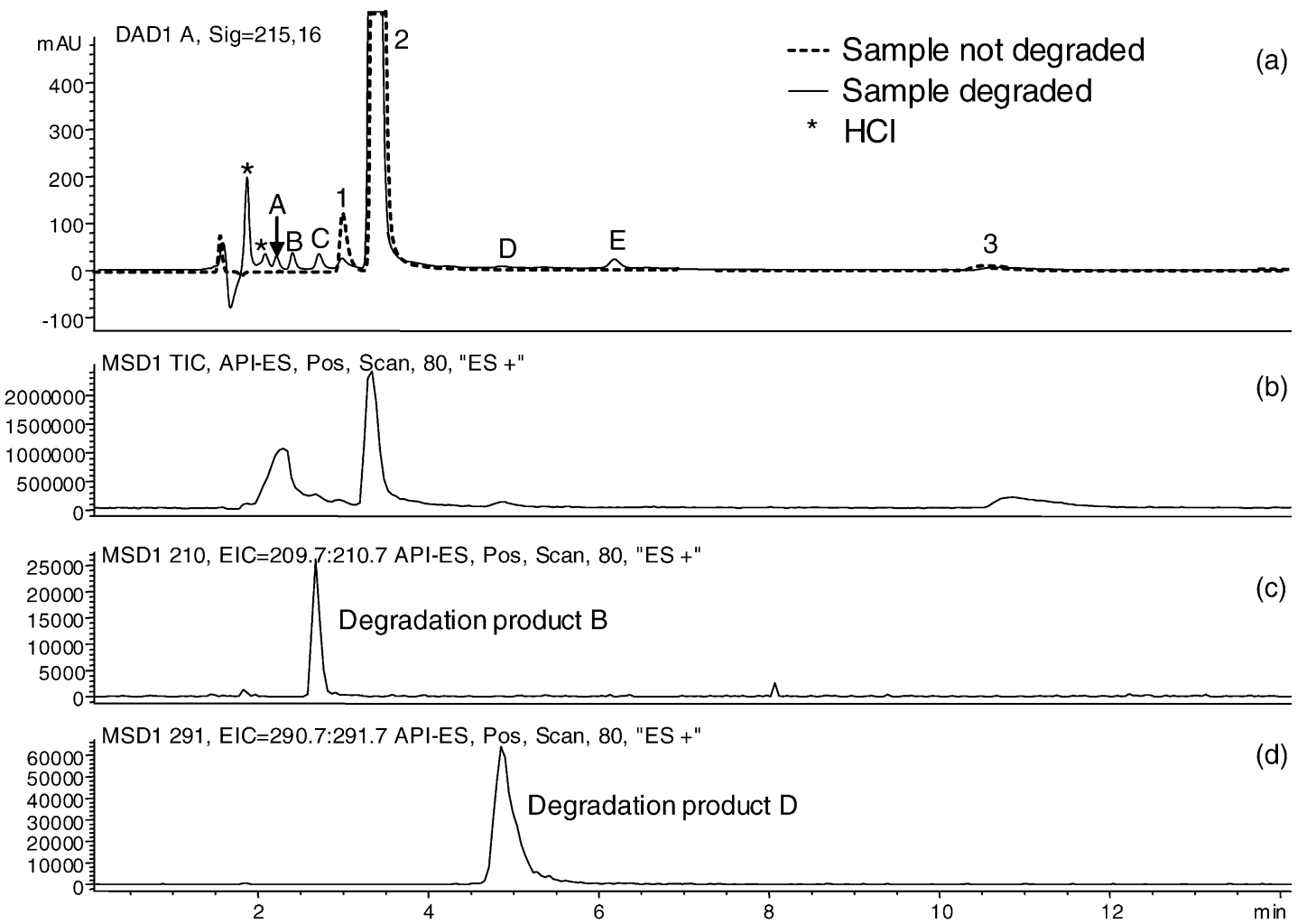

Fig. 4. Chromatograms of the sample under acidic conditions. (a) UV chromatogram at $215 \mathrm{~nm}$. (b) TIC chromatogram. (c) and (d) Extracted ions chromatograms at $\mathrm{m} / \mathrm{z} 210$ and 291, respectively. Actives compounds: 1: phenylephrine (0.2 mg/ml), 2: acetaminophen $(10 \mathrm{mg} / \mathrm{ml})$ and 3: chlorpheniramine $(0.08 \mathrm{mg} / \mathrm{ml})$. Degradation products: A-E. 


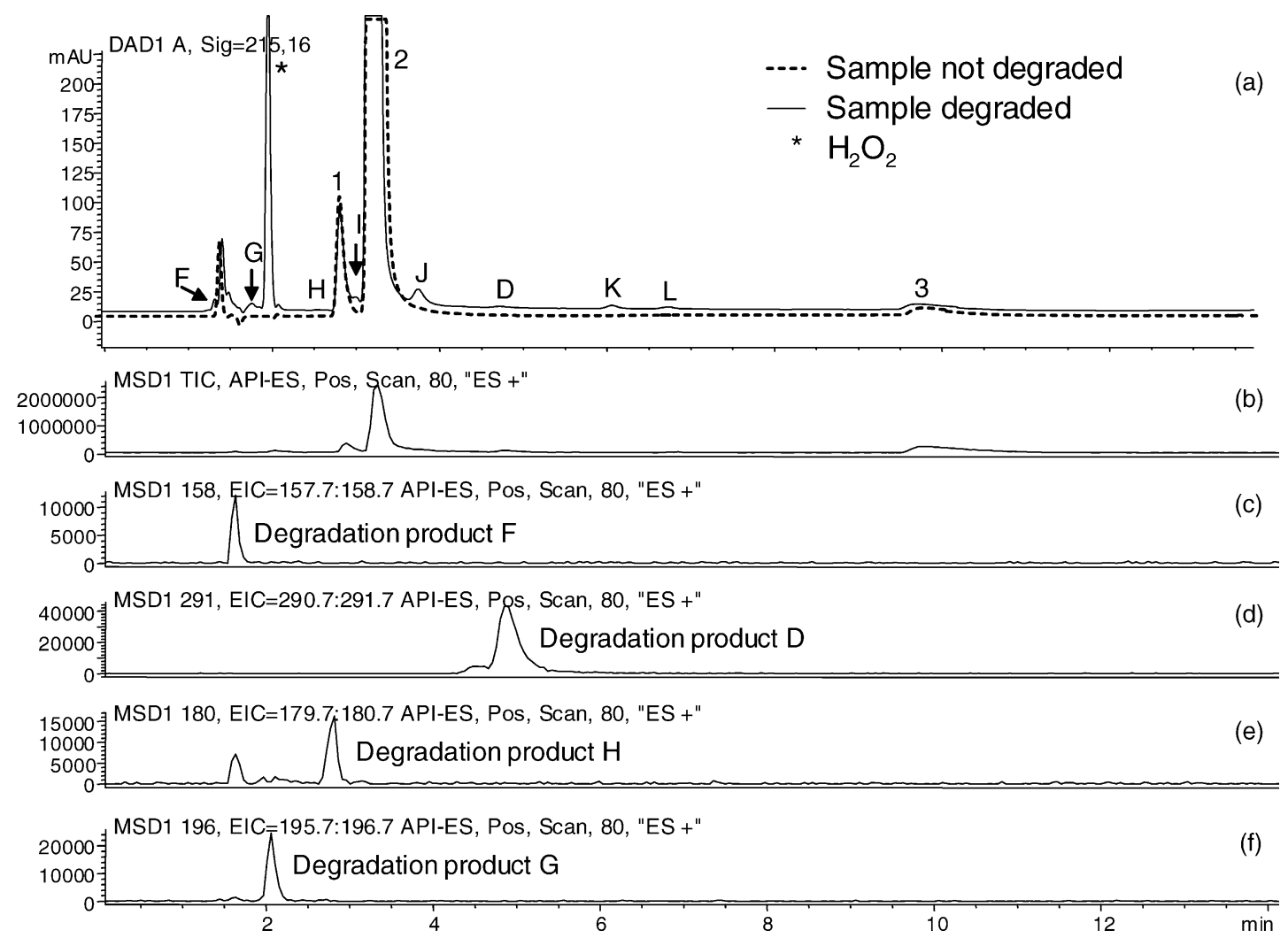

Fig. 5. Chromatograms of the sample under oxidation conditions. (a) UV chromatogram at $215 \mathrm{~nm}$. (b) TIC chromatogram. (c-f) Extracted ions chromatograms at $\mathrm{m} / \mathrm{z} 158,291,180$ and 196, respectively. Actives compounds: 1: phenylephrine $(0.2 \mathrm{mg} / \mathrm{ml}), 2$ : acetaminophen $(10 \mathrm{mg} / \mathrm{ml})$ and 3: chlorpheniramine $(0.08 \mathrm{mg} / \mathrm{ml})$. Degradation products: D, F-L.

293 that appeared under acidic conditions was found (Fig. 5d). Two degradation products coming from the active phenylephrine were detected at 1.9 and $2.7 \mathrm{~min}$, respectively. The first of them (product $\mathrm{G}$ ) showed molecular ions at $m / z 196[\mathrm{M}+\mathrm{H}]^{+}$(Fig. 5f) and the second one (product $\mathrm{H}$ ) at $m / z, 180[\mathrm{M}+\mathrm{H}]^{+}, m / z, 202$ $[\mathrm{M}+\mathrm{Na}]^{+}$and $m / z 381\left[2 \mathrm{M}+\mathrm{Na}^{+}\right]$(Fig. 5e) and, indicating they have molecular weights of 195 and $179 \mathrm{Da}$ respectively. It is important to remark that the detection of some of these peaks by UV was close to the detection limit, whereas by MS they presented good ionization. On the contrary, peaks detected by UV, were not detected by MS due to they do not present ionization and in the case of the most polar degradation compounds due to the interference of the $\mathrm{HCl}$ and $\mathrm{NaOH}$ by $\mathrm{MS}$ at the beginning of the chromatogram. That means that for this type of studies is necessary to use more than one detector in order to obtain complete information. In this sense, MS detector uses to offer more data due to its higher sensitivity than the UV detector. On the other hand, 4-aminophenol, one of the impurities of the acetaminophen, resulted very unstable under any condition, especially under basic and oxidation stress conditions, in which the degradation is total. This compound, which has a molecular weight of $109 \mathrm{Da}$, polymerises rapidly giving products until $430 \mathrm{Da}$.

In order to obtain detailed structural information on each component, separate NMR experiments are required or alternatively the use of the new advent of LC-NMR that eliminates the fraction collection step, accelerating the structural characterization work, but this was not the object of the present work. 


\section{Conclusions}

Two LC/MS methods using ammonium bicarbonate and ammonium acetate as volatile buffers were developed and applied to the degradation profile estimation of cough-cold products under stress forced conditions. Ammonium acetate permitted us the results transference between the HPLC method with UV detection and a conventional sodium phosphate buffer, and the LC/MS method with an electrospray ionization interface, used to obtain molecular weights information. Thus, when a degradation product appears through the long-term stability test routinely performed with HPLC/UV in this complex mixture, the peak assignment would be easier to estimate the percentage of related compound formed.

\section{Acknowledgements}

We would like to thank Lilly laboratories for the technical support and Cinfa laboratories for providing the test materials.

\section{References}

[1] ICH topic Q1A(R2). Stability testing of new drug substances and products, 2003. Available on: http://www.hc-sc.gc.ca/ hpfb-dgpsa/tpd-dpt/q1a(r2)_e.pdf.

[2] ICH topic Q3B(R). Impurities in new drug products, 2003. Available on: http://www.hc-sc.gc.ca/hpfb-dgpsa/tpd-dpt/q3b (r)_e.pdf.
[3] M. Bakshi, S. Singh, J. Pharm. Biomed. Anal. 28 (2002) 1011-1040.

[4] A. Marín, E. García, A. García, C. Barbas, J. Pharm. Biomed. Anal. 29 (2002) 701-714.

[5] A. García, F.J. Rupérez, A. Marín, A. de la Maza, C. Barbas, J. Chromatogr. B. 785 (2003) 237-243.

[6] D.V. McCalley, J. Chromatogr. A. 987 (2003) 17-28.

[7] P. Ross, Developing New Methods for LC/MS. Technical Bulletin 00-11. ThermoHypersil, Keystone Scientific Operations 1-6.

[8] K. Lazou, LC GC Eur. 13 (2000) 340.

[9] P. Sandra, G. Vanhoenacker, F. Lynen, L. Li, M. Schelfaut, LC GC Eur., 2001, pp. 2-14.

[10] I. Canals, K. Valko, E. Bosch, A.P. Hill, M. Rosés, Anal. Chem. 73 (2001) 4937-4945.

[11] S. Espinosa, E. Bosch, M. Rosés, J. Chromatogr. A. 947 (2002) 47-58.

[12] A. Marín, C. Barbas, J. Pharm. Biomed. Anal. (in press).

[13] A. Espada, A. Rivera-Sagredo, J. Chromatogr. A. 987 (2003) 211-220.

[14] A. Espada, A. Marín, C. Anta, J. Chromatogr. A. 1030 (2004) 43-51.

[15] N. Sagliano Jr., T.R. Floyd, R.A. Hartwick, J.M. Dibussolo, N.T. Miller, J. Chromatogr. 443 (1998) 155-172.

[16] J.J. Kirkland, M.A. van Straten, H.A. Claessens, J. Chromatogr. A. 691 (1995) 3-19.

[17] Y.F. Cheng, T.H. Walter, Z. Lu, P. Iraneta, B.A. Alden, C. Gendreau, U.D. Neue, J.M. Grassi, J.L. Carmody, J.E. O'Gara, R.P. Fisk, LC GC Eur. 18 (2000) 1162-1172.

[18] The Pharmaceutical Society of Great Britain, The Pharmaceutical Codex, 11th ed., The Pharmaceutical Press, London, 1979, p. 695.

[19] The Merck Index, An Encyclopedia of Chemicals, Drugs, and Biomedicals, thirteenth ed., Merck Research Laboratories, Division of MERCK and Co., INC., Whitehouse station, NJ.

[20] Clarke's Isolation and Identification of Drugs, second ed., The Pharmaceutical Press, London, 1986. 